\title{
Simulation study of GaAsP/Si tandem solar cells
}

\author{
Arthur Onno ${ }^{1 *}$, Nils-Peter Harder ${ }^{2}$, Lars Oberbeck $^{2}$, Huiyun Liu ${ }^{1}$ \\ ${ }^{1}$ Department of Electronic and Electrical Engineering, University College London, London WC1E 7JE, \\ United Kingdom \\ ${ }^{2}$ TOTAL New Energies R\&D Division, 24 cours Michelet, 92069 Paris La Défense Cedex, France
}

\begin{abstract}
A model, adapted from the Shockley-Queisser detailed balance model to tandem solar cells with a monolithically grown $\mathrm{GaAs}_{x} \mathrm{P}_{1-x}$ top junction on a $\mathrm{Si}$ bottom junction, has been developed. Updated data have been used for the absorption spectrums. Two surface geometries, flat and ideally textured, have been investigated. As an important improvement over existing models, the effects of threading-dislocations-related Shockley-Read-Hall recombinations in the $\mathrm{GaAs}_{x} \mathrm{P}_{1-x}$ cell, due to the lattice mismatch between the $\mathrm{GaAs}_{x} \mathrm{P}_{1-x}$ epilayers and the $\mathrm{Si}$ substrate, have been taken into consideration. Auger recombinations in the Si bottom cell and luminescent coupling between the cells have also been considered. For a dislocation-free $2-\mu \mathrm{m}$-thick top cell, maximal theoretical efficiencies of $41.6 \%$ and $39.1 \%$ have been calculated for a textured and a flat surface, respectively. For threading dislocation (TD) densities below $10^{4} \mathrm{~cm}^{-2}$, the impact of TDs in the $\operatorname{GaAs}_{x} \mathrm{P}_{1-x}$ layers on the solar cell performances is very limited. With TD densities over $10^{5} \mathrm{~cm}^{-2}$, the top cell open-circuit voltage is reduced, hence the overall efficiency. For TD densities over $4 \times 10^{6} \mathrm{~cm}^{-2}$, as the diffusion length of minority carriers in the base gets smaller than the base thickness, the short-circuit current in the top $\operatorname{GaAs}_{x} \mathrm{P}_{1-x}$ cell is also reduced, resulting in a decrease in the optimal top cell bandgap. Using non-ideal EQEs and surface recombination rates from published experimental data, the long-term efficiency potential of the investigated technology has been estimated to be $\sim 35.1 \%$ for an ideally textured $\mathrm{GaAs}_{x} \mathrm{P}_{1-x} / \mathrm{Si}$ tandem cell with a TD density of $10^{5} \mathrm{~cm}^{-2}$ $(\sim 33.0 \%$ with a flat surface).
\end{abstract}

\section{Keywords}

Threading dislocation density, Dual-junction, Silicon, GaAsP

\section{Corresponding author}

Arthur Onno, Department of Electronic and Electrical Engineering, University College London, London WC1E 7JE, United Kingdom

E-mail: arthur.onno.13@ucl.ac.uk 


\section{INTRODUCTION}

The photovoltaic industry has seen a remarkable development in the recent years, largely fueled by a continuous reduction of costs along the entire value chain. Nevertheless, further improvements are needed in order to keep this sustained pace of cost reduction and further expand the adoption of the technology. Among the multiple levers for cost reduction, improving the efficiency plays a very significant role as it impacts the cost of the whole system.

With $25.6 \%$ record efficiency and $25.0 \%$ efficiency achieved with processes used for industrial production of solar cells [1,2], the low-cost market-dominant crystalline silicon-based solar cell technology is already very close to its theoretical maximal efficiency, and the margin for further improvement is very small. On the other hand, III-V based multi-junction solar cells have been able to achieve efficiencies close to $40 \%$ without concentration $[3,4]$. However, the need for expensive substrates makes their high scale development unlikely. Although epitaxial Lift-Off (ELO) process is a solution pathway to overcome this issue [5], uncertainties remain regarding the costs and limits of substrate reuse.

The combination of III-V single- or multi-junction solar cells integrated on a comparatively low-cost silicon substrate are promising alternative candidates for cost-efficient fabrication of high efficiency solar cells. Wafer bonding circumvents issues arising from polar-on-nonpolar integration and difference in lattice constant between materials and has resulted in high efficiency devices [6]. However, the fabrication of III-V cells on distinct substrates involves a step of separation in a process akin to ELO. Challenges pertaining to this technology are thereby still a concern for wafer bonding pathways. On the other hand, direct epitaxial growth of a III-V top cell on a silicon bottom cell acting as a substrate is a very elegant and potentially industrially relevant way to produce high-efficiency tandem solar cells on a low-cost substrate. Following the initial developments by Hayashi et al. in the 1990's [7] and the work carried out by Geisz et al. [8,9] in the 2000's, the technology has seen substantial progress in the recent years with the contributions of Grassman et al. [10,11] and Lang et al. [12].

In order to prove the concept and the feasibility of high-quality III-V devices grown on Si substrates, we focus our present work on the development of a dual-junction cell, comprising a Si bottom cell and a III-V top cell. In this case, multiple generic dual-junction models [13-15] have shown that the top cell bandgap should lie between 1.6 and $1.8 \mathrm{eV}$. As there is no nitrogen-free III-V material lattice-matched to silicon in this bandgap window, a lattice-mismatched architecture is needed. In order to achieve the highest crystal perfection, the lattice mismatch should be as small as possible. Among the III-V materials, $\mathrm{GaAs}_{x} \mathrm{P}_{1-x}$ is the nitrogen-free ternary compound material in the targeted bandgap window exhibiting the smallest lattice-mismatch with silicon. Moreover, GaP is nearly lattice-matched with silicon, and therefore offers an ideal pathway for the integration of a 1.6-1.8 eV GaAs $\mathrm{P}_{1-x}$ top cell on silicon. However few material-specific and architecture-specific detailed models of such structures have been developed so far to determine the exact bandgap needed for the top cell and the parameters influencing the efficiency of the dual-junction cell. Most of the modeling work on dual-junction solar cells, including the aforementioned contributions, suffers from the lack of architecture-specific features and relies on theoretical absorption spectrums, infinite cell thickness hypothesizes or dark-current calculations based on theoretical electronic parameters or empirical relations built on outdated cell 
performances. Moreover the impact of crystal imperfections on dual-junction III-V/Si solar cells performances has not been considered in the modeling works reported in the literature, although the formation of defects is inevitable for 1.6-1.8 eV III-V materials monolithically grown on silicon substrates.

The main hurdle in accurately simulating bandgap-dependent, material-specific and architecture-specific dual-junction solar cells lies in the lack of data regarding the chosen material $\left(\mathrm{GaAs}_{x} \mathrm{P}_{1-x}\right.$ in the present work). In order to approximate the expectable behavior of the real material without using an extensive number of electronic parameters, we simulate the device performances as a result of the flow equilibrium in the cells, adapting the detailed balance model developed by Shockley and Queisser [16]. We consider the radiative limit as the upper thermodynamic boundary on the cells performances and use simple models to calculate non-radiative recombination rates, such as Auger and Shockley-Read-Hall. The need for specific electronic parameters is thus limited to its minimum as the main input in the model is the absorption spectrum of the top cell material.

As an important improvement over already existing models, the impact of threading dislocations (TDs), the main source of inefficiencies for lattice-mismatched III-V solar cells, has been integrated in the model. Additionally, the luminescent coupling between the cells due to photons from radiative recombinations in the top cell cascading to the bottom cell has also been taken into account. The impact of two geometrical architectures for the front surface (flat and ideally textured) has also been investigated. Finally, other sources of non-idealities such as non-perfect EQE and surface recombinations are added in section 3.4 in order to give an evaluation of the long-term potential performances of the technology. This comprehensive model allows for quantitative insights in the design of $\mathrm{GaAs}_{x} \mathrm{P}_{1-x} / \mathrm{Si}$ dual-junction solar cells such as the ones currently developed [10-12], highlighting the processes limiting the efficiency of the investigated architecture. Moreover, targets are set regarding the maximum threading dislocation density (TDD) needed in order to achieve very high efficiency devices $(>35 \%)$.

\section{METHOD}

The model presented hereafter has been developed using MATLAB ${ }^{\circledR}$ R2014a. All the calculations are wavelength-dependent with rectangular integration on the wavelength between 280 and $1450 \mathrm{~nm}$ with a $0.5 \mathrm{~nm}$ step. The efficiencies were calculated for air mass 1.5 global (AM1.5G) without concentration using data from the ASTM G173-03 reference spectrum [17]. The percentage of arsenic $x$ in the top $\operatorname{GaAs}_{x} \mathrm{P}_{1-x}$ cell can vary from $x=0.55$ to 1 , representing the direct bandgap domain of $\mathrm{GaAs}_{x} \mathrm{P}_{1-x}$ [18]. The main challenge in accurately simulating a bandgap-dependent $\operatorname{GaAs}_{x} \mathrm{P}_{1-x} / \mathrm{Si}$ dualjunction solar cell lies in the lack of data regarding the electronic parameters of $\mathrm{GaAs}_{x} \mathrm{P}_{1-x}$ for varying percentages of arsenic $x$. Using the blackbody theory applied to semiconductors and the flow equilibrium in the cells, our model reduces the amount of electronic parameters needed to a very limited number, namely the bandgap $E_{g}\left(G a A s_{x} P_{1-x}\right)$, the densities of states in the conduction and valence bands $N_{c}\left(G a A s_{x} P_{1-x}\right)$ and $N_{v}\left(G a A s_{x} P_{1-x}\right)$, the diffusion coefficient of electrons and holes $D_{n}\left(G a A s_{x} P_{1-x}\right)$ and $D_{p}\left(G a A s_{x} P_{1-x}\right)$ and the relative permittivity $\varepsilon_{r}\left(G a A s_{x} P_{1-x}\right)$. The formulas used for the calculation of these electronic parameters and their sources are summarized in TABLE 1 . The five last electronic parameters are moreover solely used 
for the modeling of the impact of TDs. Hence the bandgap is the single parameter needed for the determination of the perfect crystal theoretical maximal efficiency.

This is possible through the use of a thermodynamic approach exclusively based on the absorption spectrum of the material for the calculation of the radiative recombination rate. In order to determine the absorption spectrum of $\operatorname{GaAs}_{x} \mathrm{P}_{1-x}$ for different percentage of arsenic $x$, we make the hypothesis that the main consequence of the incorporation of arsenic is a blue-shift from the absorption spectrum of GaAs equal to the difference in bandgap between $\operatorname{GaAs}_{x} \mathrm{P}_{1-x}$ and GaAs. Given the very similar shape of absorption spectrums of III-V materials, this is a rational hypothesis. The GaAs absorption reference spectrum has been extrapolated based on data from Ref. [22] between 280 and $826.5 \mathrm{~nm}$ and from the fitted model from Ref. [23] based on experimental data from Ref. [24] above $826 \mathrm{~nm}$. For the bottom Si solar cell, the absorption spectrum has been extrapolated from Ref. [25].

\subsection{Cell architecture}

The cell architecture investigated here is detailed in FIGURE 1. We have concentrated our efforts on a 2-terminal contact architecture, which is the most established solar cell device architecture in practice. In this structure, the two cells are series-connected through a high bandgap buffer such as a $\operatorname{GaAs}_{x} \mathrm{P}_{1-x}$ metamorphic buffer on a $\mathrm{GaP}$ nucleation layer, as presented in Refs. [10-12]. This buffer has a wider bandgap than the top cell, and therefore acts as an essentially transparent window for the light that passes through the top cell into the bottom cell. The absorption in this buffer layer may therefore be neglected. We furthermore assume that the tunnel junction between the two cells produces only negligible resistance.

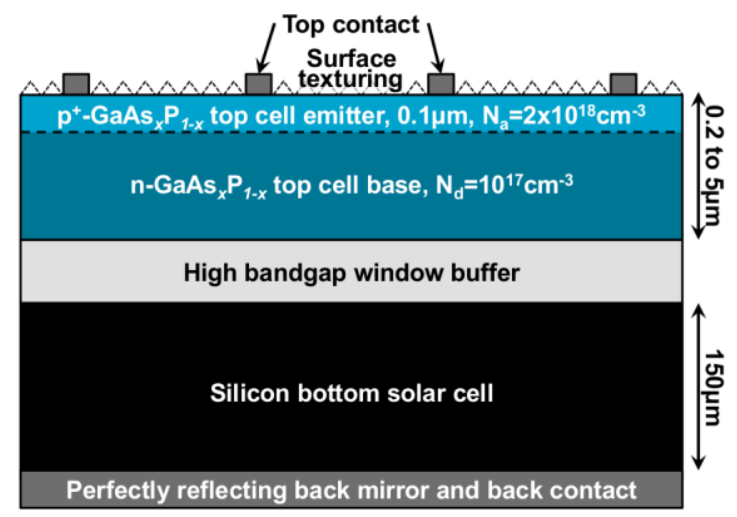

Figure 1. Detail of the architecture of the $\mathrm{GaAs}_{x} \mathrm{P}_{1-x} / \mathrm{Si}$ dual-junction investigated

The top cell material is $\operatorname{GaAs}_{x} \mathrm{P}_{1-x}$ with variable As content from $x=0.55$ to 1 and variable thickness from 0.2 to $5 \mu \mathrm{m}$. The emitter thickness is fixed at $W_{\text {emit }}=0.1 \mu \mathrm{m}$. A $\mathrm{p}^{+} / \mathrm{n}$ architecture has been chosen in order to reduce the impact of TDs, the diffusion coefficient of holes $D_{p}$ being smaller by an order of magnitude than the diffusion coefficient of electrons $D_{n}$ in $\operatorname{GaAs}_{x} \mathrm{P}_{1-x}$. Dopings of the $\mathrm{n}$-doped base and $\mathrm{p}^{+}$-doped emitter have been respectively set at $N_{d}=10^{17} \mathrm{~cm}^{-3}$ and $N_{a}=2 \times 10^{18} \mathrm{~cm}^{-3}$. Given the relatively high direct bandgap of $\mathrm{GaAs}_{x} \mathrm{P}_{1-x}$ in the range of arsenic content considered, the dominant bulk non-radiative recombination process is Shockley-Read-Hall type and Auger recombinations are neglected in the top cell. 
Charge transfer along the TDs in the top cell is possible in theory, inducing a low shunt resistance. However, a review of the literature $[9-12,26]$ shows that experimental III-V on Si solar cells for the range of TDDs investigated (up to $2 \times 10^{8}$ $\mathrm{cm}^{-2}$ ) do not exhibit such a behavior, with reported $\mathrm{J}-\mathrm{V}$ characteristics displaying flat current densities at low voltage and no evident degradation of the diodes characteristics with higher TDDs. The shunt resistances of both cells are therefore assumed infinite.

The silicon bottom cell has a thickness of $150 \mu \mathrm{m}$, representative of the industry current standards. As we want to investigate the upper limits on the efficiency of $\mathrm{GaAs}_{x} \mathrm{P}_{1-x} / \mathrm{Si}$ dual junction solar cells, we assume that extremely high quality perfectly mono-crystalline silicon is used. As threading dislocations only propagate upward through the grown III-V material due to the higher mechanical strength of silicon and the layer-by-layer method of growth, we assume the silicon cell to be defect-free. Hence we neglect Shockley-Read-Hall recombinations and only use Auger recombinations as bulk non-radiative recombinations in the bottom cell. The ambipolar Auger coefficient has been set at $C_{\text {Auger }}=1.66 \times 10^{-30} \mathrm{~cm}^{6} . \mathrm{s}^{-1}$ with an intrinsic carrier concentration of $n_{i}=9.7 \times 10^{9} \mathrm{~cm}^{-3}$ [27].

We ignore surface recombinations in both cells in the first part of the study as we focus on the impact of the threading dislocation density (TDD) on the theoretical efficiency of perfect $\mathrm{GaAs}_{x} \mathrm{P}_{1-x}$ on Si dual-junction solar cells. section 3.4, the impact of surface recombinations is added to evaluate the real-world efficiency potentially achievable by such a structure.

Two surface geometries are investigated: flat surface on one hand, ideally textured perfectly randomizing the flux on the other hand. The refractive index inside the device is supposed constant at $n_{r e f}=3.5$, which is a reasonable approximation for the materials considered. A perfectly reflecting mirror on the back of the bottom cell is assumed, doubling the optical path in the bottom cell and eliminating dark-current reemissions from the back side of the cell. Shading from the front contact and reflection at the front surface are neglected in the first part of the study. An average External Quantum Efficiency (EQE), taking into account the effect of optical losses such as grid shading and reflection on the front surface, is added section 3.4 to evaluate the real-world potential the structure.

\subsection{Blackbody theory and flow equilibrium model basics}

For each cell, we consider the well-known general diode equation:

$$
J(V)=J_{s c}+q R_{r, r a d}\left(1-e^{\frac{q V}{k_{B} T}}\right)+q \sum_{m} R_{r, m}\left(1-e^{\frac{q V}{n_{m} k_{B} T}}\right)
$$

where $J$ is the current density, $V$ the voltage, $q$ the elementary charge, $k_{B}$ the Boltzmann constant, $T$ the cell temperature set at $300 \mathrm{~K}, J_{s c}$ the short-circuit current density, $R_{r, r a d}$ the radiative recombination rate, $R_{r, m}$ the recombination rates for different non-radiative recombination mechanisms and $n_{m}$ the associated ideality factors.

In order to calculate the radiative recombination rate of each cell, we consider the flow equilibrium in the cell in the dark. Using the blackbody theory extended to semiconductors developed by Würfel [28], the emission rate of each cell in the dark under ideal conditions (no non-radiative recombinations) and considering the Bose- 
Einstein approximation $\left(E>>k_{B} T\right)$, equal to the dark-current radiative recombination rate, is given by:

$$
\int_{0}^{+\infty} \frac{2 \pi a(E) E^{2}}{h^{3} c^{2}} e^{\frac{q V-E}{k_{B} T}} d E=e^{\frac{q V}{k_{B} T}} \int_{0}^{+\infty} \frac{2 \pi c a(\lambda)}{\lambda^{4}} e^{-\frac{h c}{\lambda k_{B} T}} d \lambda
$$

where $a(\lambda)$ is the wavelength-dependent absorptivity of the cell, $E$ the energy of the photons considered, $\lambda$ their wavelength, $h$ the Planck constant and $c$ the speed of light.

We therefore have:

$$
R_{r, \text { rad }}=\int_{0}^{+\infty} \frac{2 \pi c a(\lambda)}{\lambda^{4}} e^{-\frac{h c}{\lambda k_{B} T}} d \lambda
$$

Under the initial hypothesis that at $\mathrm{V}=0$ the recombination contributions are null, the short-circuit current density $J_{s c}$ is equal to the photocurrent density $J_{p h}$, given by basically counting the number of photons absorbed within each cell, assuming perfect external quantum efficiency:

$$
\begin{gathered}
J_{p h, t o p}=q \int_{0}^{+\infty}\left(\frac{\lambda}{h c}\right) I(\lambda) a_{\text {front }, \text { top }}(\lambda) d \lambda=q R_{g, t o p} \\
J_{p h, b o t}=q \int_{0}^{+\infty}\left(\frac{\lambda}{h c}\right) I(\lambda)\left(1-a_{\text {front }, \text { top }}\right) a_{\text {front }, \text { bot }}(\lambda) d \lambda=q R_{g, b o t}
\end{gathered}
$$

where $I(\lambda)$ is the wavelength-dependent AM1.5 irradiance, $a_{\text {front,top/bot }}(\lambda)$ is the absorptivity from the front of the top/bottom cell and $R_{g}$ is the photo-generation rate.

It is to be noted that the assumption of $J_{s c}=J_{p h}$ does not take into account possible recombinations at short-circuit. The underlying hypothesis is that the diffusion lengths of minority carriers are longer than the thickness of the base and emitter and charges can travel freely to the depletion zone under short-circuit conditions. Though this hypothesis is valid when the crystal is assumed perfect, defects such as threading dislocations will reduce the diffusion length and the short-circuit current density $J_{s c}$ will be smaller than the photocurrent density $J_{p h}$. A solution to this issue is proposed and implemented in our model in section 2.4. Also note that, for the bottom cell, the total absorptivity and the absorptivity from the front surface are equal due to the presence of a back mirror so that $a_{b a c k, b o t}=0$ and $a_{b o t}(\lambda)=a_{\text {front }, \text { bot }}(\lambda)$. However, for the top cell, the total absorptivity is the sum of the front and back absorptivities: $a_{\text {top }}(\lambda)=a_{\text {front,top }}(\lambda)+a_{\text {back,top }}(\lambda)$; only the former being taken into account in the calculation of $J_{p h, t o p}$.

As specified in section 2.1, Auger recombinations are neglected in the top cell, Shockley-Read-Hall recombinations are neglected in the bottom cell and surface recombinations are neglected in both cells so that:

$$
\begin{aligned}
& J_{\text {to } p}\left(V_{\text {top }}\right)=q\left(R_{g, t o p}+R_{r, \text { rad }, \text { top }}\left(1-e^{\frac{q V_{t o p}}{k_{B} T}}\right)+R_{r, S R H}\left(V_{\text {top }}\right)\right) \\
& J_{\text {bot }}\left(V_{\text {bot }}\right)=q\left(R_{g, b o t}+R_{r, \text { rad }, \text { bot }}\left(1-e^{\frac{q V_{b o t}}{k_{B} T}}\right)+R_{r, \text { Auger }}\left(V_{\text {bot }}\right)\right)
\end{aligned}
$$


where $R_{r, S R H}(V)$ is the voltage-dependent Shockley-Read-Hall recombination rate in the top cell and $R_{r, \text { Auger }}(V)$ is the voltage-dependent Auger recombination rate in the bottom cell.

\subsection{Absorptivity model depending on front surface geometry}

As shown in FIGURE 2, absorptivities of both cells depend on the front surface geometry. Two geometries, planar and perfectly random, are investigated. As stated in section 2.2, the absorptivities $a_{\text {front,top }}$ and $a_{\text {back,top }}$ from the front and back of the top cell need to be calculated whereas only the front absorptivity $a_{\text {front,bot }}=a_{b o t}$ is needed for the bottom cell due to the presence of a perfect back mirror.
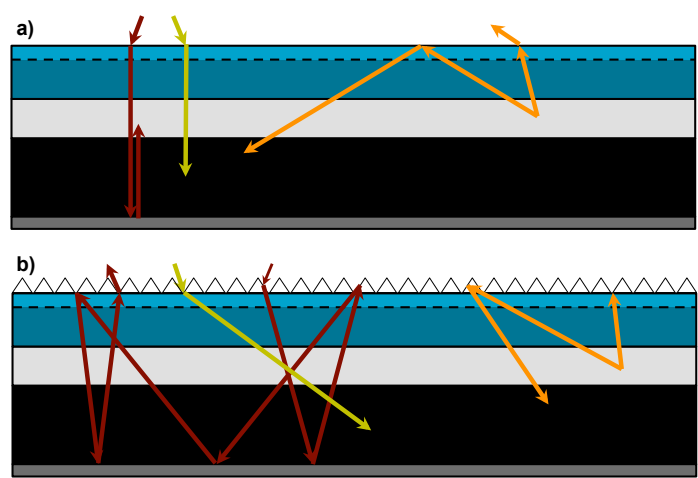

Figure 2. Schematic of the two different absorptivity models used: flat surface (a) and ideally randomly textured surface (b). The impact of the randomly textured surface is greater on the bottom cell absorptivity than on the top cell one.

\section{A. Planar front surface}

Because of the large refractive index of $\operatorname{GaAs}_{x} \mathrm{P}_{1-x}$, the incident light is refracted with an angle very close to perpendicular inside the cell. The wavelength-dependent front surface absorptivity of the top cell is thus well known:

$$
a_{\text {front }, \text { top }}(\lambda)=1-e^{-\alpha_{\text {GaAsP }}(\lambda) L_{\text {top }}}
$$

where $\alpha_{G a A s P}(\lambda)$ is the wavelength-dependent absorption coefficient of $\operatorname{GaAs}_{x} \mathrm{P}_{1-x}$ and $L_{\text {top }}$ is the top cell thickness. Similarly the wavelength-dependent front surface absorptivity of the bottom cell is:

$$
a_{\text {front }, b o t}(\lambda)=1-e^{-2 \alpha_{S i}(\lambda) L_{b o t}}
$$

where $\alpha_{S i}(\lambda)$ is the wavelength-dependent absorption coefficient of $\mathrm{Si}$ and $L_{b o t}$ is the bottom cell thickness, the optical pathlength being doubled due to the presence of a back mirror.

As previously shown in Ref. [23], absorptivity from the back side of the top cell has to take into account the increase due to the possible total internal reflection on the front side of the cell. This internal reflection happens when the incident angle is superior to the critical escape angle $\theta_{\text {esc }}=\arcsin \left(1 / n_{\text {ref }}\right)$ and doubles the effective optical pathlength. A factor $n_{r e f}^{2}$ also has to be added, the density of states of the internal blackbody radiation being multiplied by this factor, so that: 


$$
\begin{aligned}
a_{\text {back,top }}(\lambda)= & 2 n_{\text {ref }}^{2}\left(\int_{0}^{\theta_{e s c}}\left(1-e^{-\alpha_{G a A s P}(\lambda) \frac{L_{t o p}}{\cos \theta}}\right) \cos \theta \sin \theta d \theta\right. \\
& \left.+\int_{\theta_{e s c}}^{\frac{\pi}{2}}\left(1-e^{-2 \alpha_{G a A s P}(\lambda) \frac{L_{t o p}}{\cos \theta}}\right) \cos \theta \sin \theta d \theta\right)
\end{aligned}
$$

\section{B. Randomly textured surface}

In the case of a randomly textured surface, the assumption of perpendicular light entering the cell is no longer valid and the absorption in the top cell is dependent on the polar angle $\theta$. If we consider that the textured front surface is ideal and completely randomizes the incident light into a Lambertian distribution, the top cell front absorptivity is then:

$$
a_{\text {front }, \text { top }}(\lambda)=2 \int_{0}^{\frac{\pi}{2}}\left(1-e^{-\alpha_{G a A s P}(\lambda) \frac{L_{t o p}}{\cos \theta}}\right) \cos \theta \sin \theta d \theta
$$

For the bottom cell, as the top cell and buffer are windows for the wavelengths in the weakly absorbing limit, the light trapping can be considered ideal and, as shown in [29], we have:

$$
a_{\text {front }, b o t}(\lambda)=\frac{4 n_{r e f}^{2} \alpha_{S i}(\lambda) L_{b o t}}{1+4 n_{r e f}^{2} \alpha_{S i}(\lambda) L_{b o t}}
$$

Again, the absorptivity from the back of the top cell has to take into account the possible total internal reflection on the front side of the cell. However this time the angle at which the incident light encounter the surface and the angle at which it is reflected are both random so that:

$$
\begin{aligned}
& a_{\text {back,top }}(\lambda)=2 n_{\text {ref }}^{2}\left(\frac { 2 \theta _ { e s c } } { \pi } \int _ { 0 } ^ { \frac { \pi } { 2 } } \left(1-e^{\left.-\alpha_{G a A s P}(\lambda) \frac{L_{t o p}}{\cos \theta}\right)} \cos \theta \sin \theta d \theta\right.\right. \\
& \left.+\left(1-\frac{2 \theta_{e s c}}{\pi}\right) \int_{0}^{\frac{\pi}{2}} \int_{0}^{\frac{\pi}{2}}\left(1-e^{-2 \alpha_{G a A s P}(\lambda)\left(\frac{L_{t o p}}{\cos \theta}+\frac{L_{t o p}}{\cos \theta^{\prime}}\right)}\right) \cos \theta \cos \theta^{\prime} \sin \theta d \theta d \theta^{\prime}\right)
\end{aligned}
$$

\subsection{Model for bulk non-radiative recombinations}

For the bottom cell, we consider intrinsic or very low doping density silicon in order to simplify the model and reduce the Auger recombination rate, although this hypothesis does not exactly corresponds to state-of-the-art high-efficiency silicon solar cells currently available. The voltage-dependent Auger recombination rate is then given by:

$$
R_{r, \text { Auger }}(V)=C_{\text {Auger }} L_{b o t} n_{i, S i}^{3}\left(1-e^{\frac{3 q V}{2 k_{B} T}}\right)=R_{r, \text { Auger }}\left(1-e^{\frac{3 q V}{2 k_{B} T}}\right)
$$


where $L_{b o t}$ is the thickness of the bottom cell.

We consider that the only source of Shockley-Read-Hall recombinations in the top cell is the presence of TDs due to the lattice mismatch between $\mathrm{Si}$ and $\mathrm{GaAs}_{x} \mathrm{P}_{1-x}$, other crystal defects being neglected. Yamaguchi et al. have shown that, for both types of carriers, the minority-carrier diffusion length associated with a TD density $N_{T D}$ is [30]:

$$
L_{T D}=\sqrt{\frac{4}{\pi^{3} N_{T D}}}
$$

Although this model is very basic and do not describe in details the SRH recombination process on a TD, in particular regarding possible inelastic processes during the capture on deep TD energy levels, it has shown excellent agreement with experimental data in predicting the minority carrier lifetime, the open-circuit voltage and the efficiency of III-V on Si solar cells [30-37]. The voltage-dependent recombination rate associated with TDs in the depletion zone is then given by [30]:

$$
\begin{aligned}
R_{r, S R H, D Z}(\mathrm{~V})= & \frac{n_{i, G a A s P} W_{D}}{2} \frac{D_{p}}{L_{T D}^{2}}\left(1-e^{\frac{q V}{2 k_{B} T}}\right) \\
& =\frac{\pi^{3} D_{p} N_{T D} n_{i, G a A s P} W_{D}}{8}\left(1-e^{\frac{q V}{2 k_{B} T}}\right) \\
& =R_{r, S R H, D Z}\left(1-e^{\frac{q V}{2 k_{B} T}}\right)
\end{aligned}
$$

where $D_{p}$ is the minority-carrier diffusion coefficient of holes and $W_{D}$ is the depletion width of the top cell given by:

$$
W_{D}=\sqrt{\frac{2 \varepsilon_{0} \varepsilon_{r}}{q} \frac{k_{B} T}{q} \ln \left(\frac{N_{a} N_{d}}{n_{i, G a A s P}^{2}}\right)\left(\frac{1}{N_{a}}+\frac{1}{N_{d}}\right)}
$$

and $n_{i}$ is calculated using the usual relation:

$$
n_{i, G a A s P}=\sqrt{N_{c} N_{v}} e^{-\frac{E_{g}}{2 k_{B} T}}
$$

In the base and in the emitter, the voltage-dependent recombination rates associated with TDs are given by [38]:

$$
\begin{aligned}
R_{r, S R H, \text { base }}(V) & =\frac{n_{i, G a A s P}^{2} W_{\text {base }}}{N_{d}} \frac{D_{p}}{L_{T D}^{2}}\left(1-e^{\frac{q V}{k_{B} T}}\right) \\
& =\frac{\pi^{3} D_{p} N_{T D} n_{i, G a A s P}^{2} W_{\text {base }}}{4 N_{d}}\left(1-e^{\frac{q V}{k_{B} T}}\right) \\
& =R_{r, S R H, \text { base }}\left(1-e^{\frac{q V}{k_{B} T}}\right)
\end{aligned}
$$




$$
\begin{aligned}
R_{r, \text { SRH }, \text { emit }}(V) & =\frac{n_{i, G a A s P}^{2} W_{e m i t}}{N_{a}} \frac{D_{n}}{L_{T D}^{2}}\left(1-e^{\frac{q V}{k_{B} T}}\right) \\
& =\frac{\pi^{3} D_{n} N_{T D} n_{i, G a A s P}^{2} W_{e m i t}}{4 N_{a}}\left(1-e^{\frac{q V}{k_{B} T}}\right) \\
& =R_{r, \text { SRH }, \text { emit }}\left(1-e^{\frac{q V}{k_{B} T}}\right)
\end{aligned}
$$

where $D_{n}$ is the minority-carrier diffusion coefficient of electrons, $W_{\text {base }}$ is the top cell base width and $W_{\text {emit }}$ is the top cell emitter width.

The Shockley-Read-Hall recombination rate in the quasi-neutral region can then be written from equations (19) and (20):

$$
\begin{aligned}
R_{r, S R H, Q N R}(V) & =R_{r, S R H, \text { base }}(V)+R_{r, S R H, \text { emit }}(V) \\
& =\left(R_{r, S R H, \text { base }}+R_{r, S R H, \text { emit }}\right)\left(1-e^{\frac{q V}{k_{B} T}}\right) \\
& =R_{r, S R H, Q N R}\left(1-e^{\frac{q V}{k_{B} T}}\right)
\end{aligned}
$$

The reduced diffusion length will also impact the photon collection and therefore the short-circuit current as only a portion of the photo-generated carriers will be able to reach the depletion zone. We can assume that the photon collection efficiency will not be impacted in the emitter zone as its thickness is smaller than the diffusion length, even for very high TD densities (up to $N_{T D}=10^{9} \mathrm{~cm}^{-2}$ ). The carriers generated in the depletion zone will also all be collected.

However, under the approximation of a uniform generation rate, the carriers generated in the base at a distance from the depletion zone larger than the diffusion length will not contribute to the short-circuit current. This means that, for the calculation of the top cell photo-generated current in absorptivity equations (8-13), the actual thickness of the cell $L_{\text {top }}$ must be replaced by an effective thickness $L_{t o p}{ }^{\prime}=W_{\text {emit }}+W_{D}+L_{T D}$ when $L_{\text {top }}{ }^{\prime}<L_{\text {top }}$. The decrease of the short-circuit current at higher TDDs, due to the reduced minority carriers diffusion length, is therefore integrated by evaluating the photocurrent over a thickness smaller than the actual geometrical thickness of the top cell. For a $2-\mu \mathrm{m}$-thick cell, this will be the case for a TD density $N_{T D}>4 \times 10^{6} \mathrm{~cm}^{-2}$. As shown in Ref. [39] for a cell with a $2.5-\mu \mathrm{m}$-thick base, a lower TD density $\left(N_{T D}=0.8\right.$ $\left.1.5 \times 10^{6} \mathrm{~cm}^{-2}, L_{T D}=2.9-4 \mu \mathrm{m}\right)$ already has a strong impact on the open-circuit voltage but no noticeable effect on the external quantum efficiency and therefore on the short-circuit current.

Current-voltage characteristics in the top and bottom cells are then given by:

$$
\begin{gathered}
J_{\text {top }}\left(V_{\text {top }}\right)=q\left(R_{g, \text { top }}+\left(R_{r, \text { rad }, \text { top }}+R_{r, S R H, Q N R}\right)\left(1-e^{\frac{q V_{t o p}}{k_{B} T}}\right)\right. \\
\left.+R_{r, S R H, D Z}\left(1-e^{\frac{q V_{t o p}}{2 k_{B} T}}\right)\right) \\
J_{b o t}\left(V_{b o t}\right)=q\left(R_{g, b o t}+R_{r, \text { rad }, \text { bot }}\left(1-e^{\frac{q V_{b o t}}{k_{B} T}}\right)+R_{r, \text { Auger }}\left(1-e^{\frac{3 q V_{b o t}}{2 k_{B} T}}\right)\right)
\end{gathered}
$$




\subsection{Luminescent coupling between the cells}

An additional process taken into account is the luminescent coupling between the cells, as photons emitted through radiative recombinations in the top cell can cascade to the bottom cell. This process has been extensively documented and modeled by Friedman, Geisz and Steiner [40-42]. In a first approximation, regardless of the surface geometry, the probability of a reemitted photon to escape through the top surface is $\theta_{\text {esc }} / \pi$ so the probability of cascading to the bottom cell is $1-\left(\theta_{\text {esc }} / \pi\right)$. These photons have energies close to the bandgap of the top cell, in the very high absorption region of the bottom cell absorption spectrum. We can therefore assume that all these photons will contribute to the photocurrent in the bottom cell. The boost to the bottom cell photocurrent density from the coupling is then:

$$
J_{p h, L C, \text { bot }}\left(V_{\text {top }}\right)=q\left(1-\frac{\theta_{\text {esc }}}{\pi}\right) R_{r, \text { rad }, \text { top }} e^{\frac{q V_{t o p}}{k_{B} T}}
$$

The cells being series-connected, we have $J=J_{t o p}=J_{b o t} . V_{\text {top }}$ and $V_{\text {bot }}$ can then be expressed as a function of one another through:

$$
\begin{gathered}
R_{g, \text { top }}+\left(R_{r, \text { rad }, \text { top }}+R_{r, S R H, Q N R}\right)\left(1-e^{\frac{q V_{t o p}}{k_{B} T}}\right)+R_{r, S R H, D Z}\left(1-e^{\frac{q V_{t o p}}{2 k_{B} T}}\right) \\
=R_{g, b o t}-\left(1-\frac{\theta_{\text {esc }}}{\pi}\right) R_{r, \text { rad }, \text { top }}\left(1-e^{\frac{q V_{t o p}}{k_{B} T}}\right)+R_{r, \text { rad }, \text { bot }}\left(1-e^{\frac{q V_{b o t}}{k_{B} T}}\right) \\
+R_{r, \text { Auger }}\left(1-e^{\frac{3 q V_{b o t}}{2 k_{B} T}}\right)
\end{gathered}
$$

The efficiency of the tandem cell can subsequently be calculated by finding the maximum of $J\left(V_{t o p}+V_{b o t}\right)$ corresponding to the maximum power point of the dualjunction cell.

\section{RESULTS AND DISCUSSION}

\subsection{Impact of the luminescent coupling}

FIGURE 3 shows theoretical isoefficiency contours as a function of the top cell thickness and the top cell bandgap with (3a) and without (3b) taking into account the impact of the luminescent coupling. We have considered a flat-surface dual-junction solar cell with no TDs (no SRH recombinations). The dashed line represents the optimal bandgap of the top cell as a function of its thickness. The diamond-shaped dots represent the particular case of a $1.6 \mathrm{eV}, 2-\mu \mathrm{m}$-thick top cell whose $\mathrm{J}-\mathrm{V}$ curves with and without luminescent coupling are detailed in FigurE 4. The luminescent coupling can greatly improve the efficiency of the stack for non-optimal bandgap/thickness combinations by rebalancing the currents between the cells. As demonstrated in Ref. [43], this process greatly improves the flexibility in the design and the operation of such a dual-junction solar cell, as a non-optimal top cell bandgap or non-ideal conditions - such as high temperatures or an incident spectrum different from AM1.5 - will have a reduced impact on the cell performances.

The coupling process only happens on the left of the dashed line, when a too high photocurrent is produced in the top cell due to its bandgap being smaller than optimal as shown in FIGURE 4. The operating voltage of the top cell (colored dots) will then be higher than the maximum power-point of the individual cell in order to match the 
currents in the two cells, leading to an increased top cell radiative recombination current $J_{r, \text { rad,top }}$. A majority of the associated photons will cascade to the bottom cell. This additional current $J_{p h, L C, b o t}$ in the bottom cell will reduce the imbalance between the currents in the two cells. In the case presented, the short-circuit current of the bottom cell is increased from $15.4 \mathrm{~mA} . \mathrm{cm}^{-2}$ to $20.0 \mathrm{~mA} \cdot \mathrm{cm}^{-2}$, representing an improvement of over $30 \%$ of the tandem cell short-circuit current and, as the bottom cell current is the limiting one, of the final tandem cell efficiency. If the top cell bandgap is too high, as shown on the right of the dashed line on FIGURE 3a, this process cannot happen as the current will be in excess in the bottom cell. The energy of the luminescent photons generated by radiative recombinations in the bottom cell will be too low for them to be absorbed in the top cell and this cascading process will not occur.
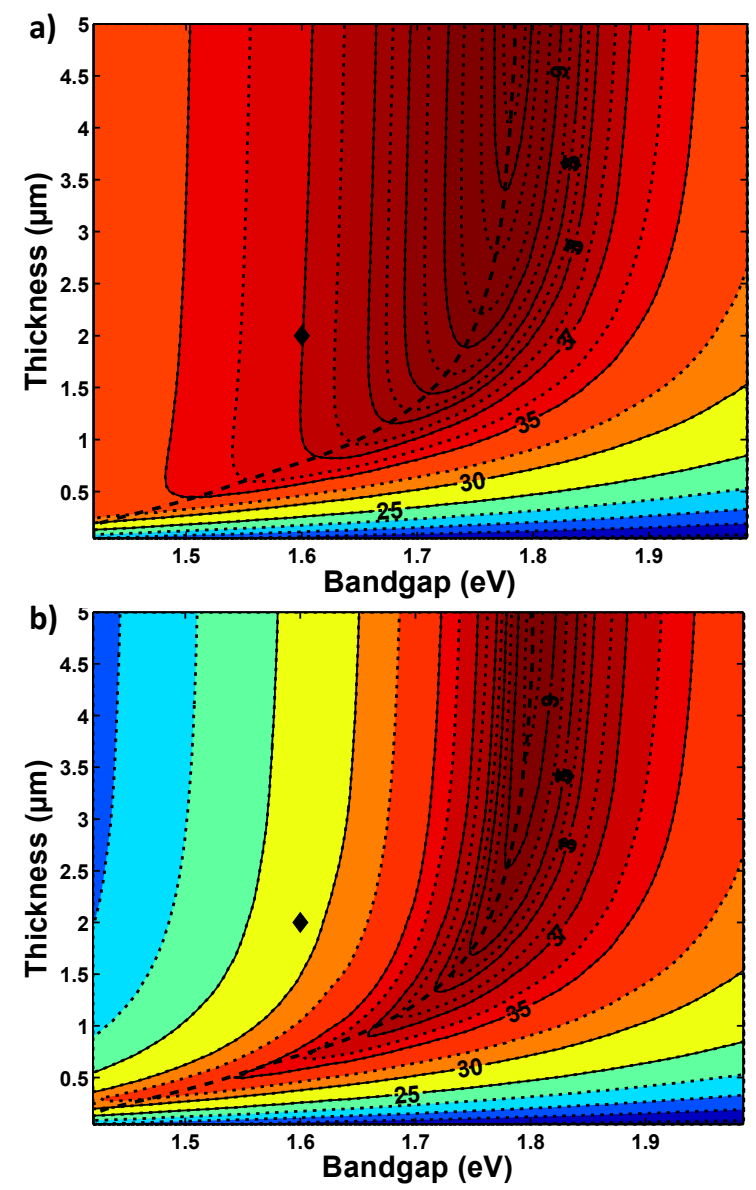

Figure 3. Maximal theoretical efficiency of a flat surface $\mathrm{GaAs}_{x} \mathrm{P}_{1-x} / \mathrm{Si}$ dual-junction solar cell as a function of the top cell bandgap and thickness, with (a) and without (b) taking into account the luminescent coupling. The dashed line represents the optimal bandgap depending on the top cell thickness. The diamond-shaped dots represent the conditions detailed in FIGURE 4. 


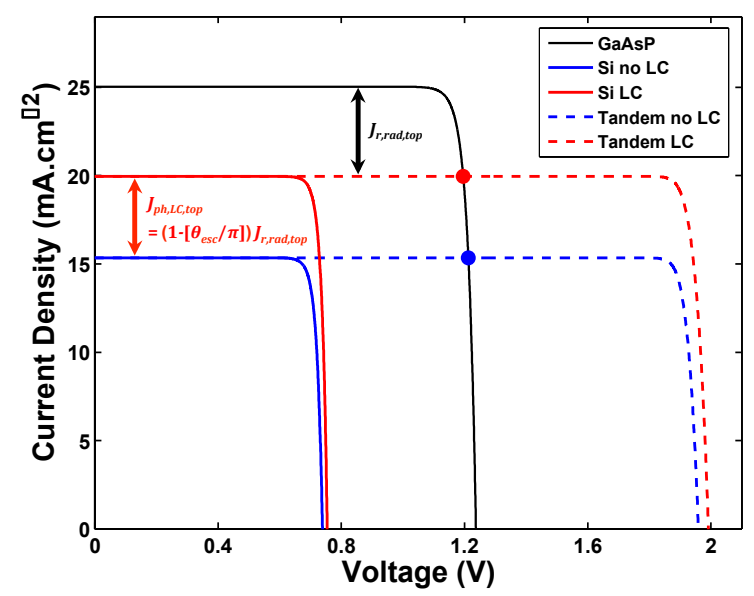

Figure 4. J-V characteristics of the GaAsP top (full black line), Si bottom (full colored lines) and GaAsP/Si tandem (dashed colored lines) cells with (red lines) and without (blue lines) taking into account the luminescent coupling (LC). The blue and red dots represent the lower boundaries on the voltage of the GaAsP top cell to ensure current matching between the cells with and without LC.

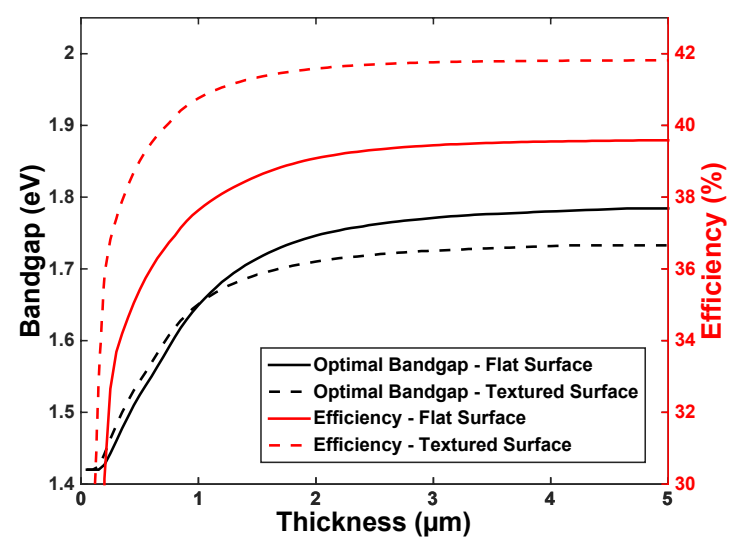

Figure 5. Efficiency (in red, right scale) and optimal top cell bandgap (in black, left scale) as a function of the top cell thickness for flat surface (full line) and ideally textured surface (dashed line) $\mathrm{GaAs}_{x} \mathrm{P}_{1-x} / \mathrm{Si}$ dual-junction solar cell.

\subsection{Impact of top cell thickness and surface texturing}

FIGURE 5 shows the maximal theoretical efficiency (in red, right scale) and the optimal top cell bandgap (in black, left scale) as a function of the top cell thickness $L_{\text {top }}$ for both surface geometries investigated with no TDs (no SRH recombinations). When $L_{\text {top }}$ is higher than $1.5 \mu \mathrm{m}$, the surface geometry does not only have an impact on the efficiency of the dual-junction cell but also on the optimal bandgap of the top cell. This is due to the strong increase in absorptivity in the bottom cell with a textured surface while the absorptivity in the top cell is only slightly impacted. This difference in optimal top cell bandgaps can represent up to $0.05 \mathrm{eV}(1.73 \mathrm{eV}$ for the textured cell versus $1.78 \mathrm{eV}$ for the flat cell) for $L_{\text {top }}$ higher than $4 \mu \mathrm{m}$. A smaller bandgap in the top cell is then needed to balance the currents in the two cells. The top cell current is thus increased while the bottom cell current is decreased. However, for very thin top cells (less than $1 \mu \mathrm{m}$ ), the impact of the textured surface on the top cell absorptivity is way stronger and counterbalances the increase in absorptivity in the 
bottom cell. Therefore the optimal bandgaps are nearly identical for both surface configurations.

For the same reasons, the impact of the textured surface on the efficiency of the dual-junction solar cell is higher for top cells less than $1-\mu \mathrm{m}$ thick, as the improvement in absorptivity happens in both cells. For thicker top cells, a textured surface has a smaller effect on the overall efficiency. The maximal theoretical efficiency for the highest top cell thickness investigated $(5 \mu \mathrm{m})$ is $41.8 \%$ with a textured surface and $39.6 \%$ with a flat surface.

The overall efficiency increases with the top cell thickness although it is plateauing above a certain thickness. For a flat surface cell, a $1-\mu$ m-thick top cell is able to achieve an efficiency of $37.6 \%$ while a $2.2-\mu \mathrm{m}$-thick achieves $39.2 \%$. This respectively represents $95 \%$ and $99 \%$ of the highest theoretical efficiency calculated. For a textured surface, $0.7-\mu \mathrm{m}$ and $1.6-\mu \mathrm{m}$ top cell thicknesses are respectively able to achieve efficiencies of $39.7 \%$ and $41.4 \%$, representing $95 \%$ and $99 \%$ of the highest calculated efficiency. A $2-\mu \mathrm{m}$ top cell thickness as therefore been chosen for the following simulations. For a dual-junction solar cell with a flat surface, this represents a maximal theoretical efficiency of $39.1 \%$ and an optimal top cell bandgap of $1.75 \mathrm{eV}$. With a textured surface the efficiency increases to $41.6 \%$ with a top cell optimal bandgap of $1.71 \mathrm{eV}$.

\subsection{Impact of the threading dislocation density}

FIGURE 6 shows the impact of the TDD, $N_{T D}$ on the efficiency of a $\operatorname{GaAs}_{x} \mathrm{P}_{1-x} / \mathrm{Si}$ dualjunction solar cell with a $2-\mu \mathrm{m}$-thick top cell and flat and textured surfaces. FIGURE 6a) displays the theoretical maximal efficiency as a function of the top cell bandgap and the TDD only for a flat surface. FIGURE 6b) shows the theoretical maximal efficiency and the optimal bandgap as a function of the TDD for both surface geometries. Low densities $\left(N_{T D}<10^{4} \mathrm{~cm}^{-2}\right)$ of TDs barely have any impact on the maximal efficiency or the optimal bandgap. When the TDD is above $10^{4} \mathrm{~cm}^{-2}$ $\left(N_{T D}>10^{4} \mathrm{~cm}^{-2}\right)$, the efficiency begins to slowly drop as a result of the reduction in the open-circuit voltage and fill factor of the top cell due to the increased ShockleyRead-Hall recombination rate associated with TDs. This is clear in FIGURE 7, where the drop of $V_{o c}$ of the dual-junction solar cell is evident for $N_{T D}>10^{4} \mathrm{~cm}^{-2}$. However, the short-circuit current of the top cell is not impacted and its optimal bandgap is only slightly impacted up to $N_{T D} \approx 4 \times 10^{6} \mathrm{~cm}^{-2}$. When the TDD is increased above $4 \times 10^{6}$ $\mathrm{cm}^{-2}\left(N_{T D}>4 \times 10^{6} \mathrm{~cm}^{-2}\right)$, the diffusion length of the minority carriers in the base is smaller than the base thickness and the collection of photo-generated charge carriers begins to drop as well. The short-circuit current of the top cell is therefore reduced, as shown in FIGURE 8 and a lower top cell bandgap is needed to rebalance the currents between the two cells. 

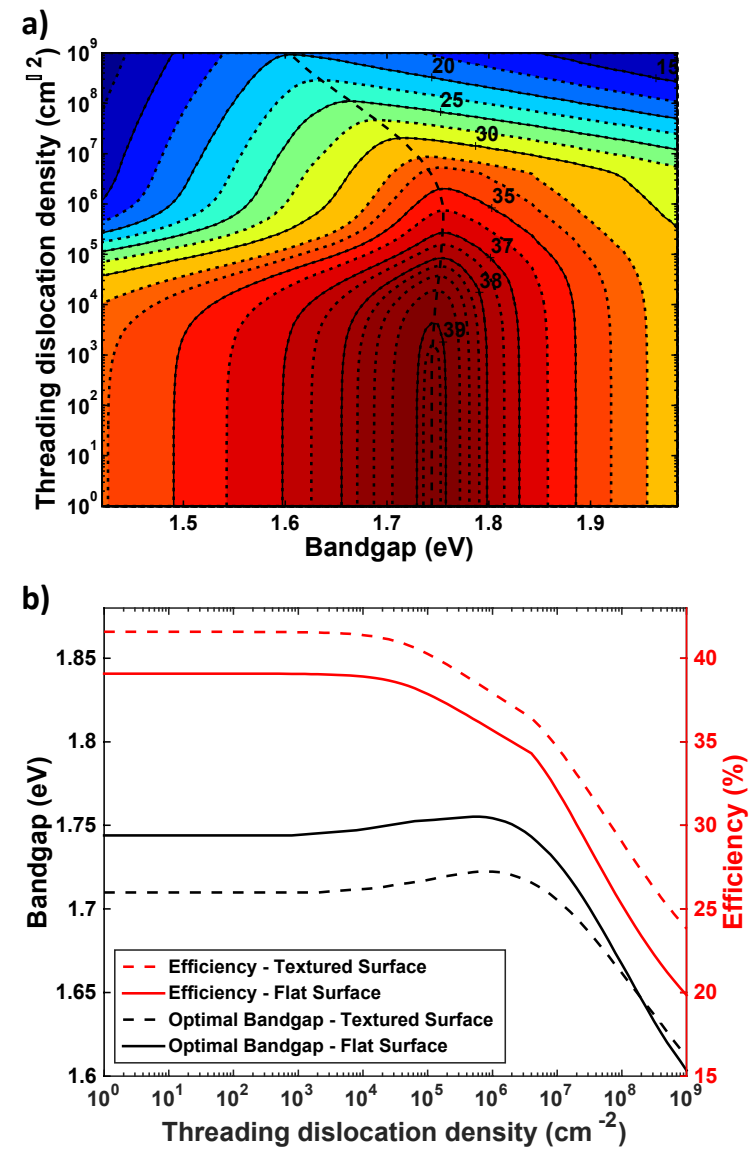

Figure 6. a) Maximal theoretical efficiency of a flat surface $\mathrm{GaAs}_{x} \mathrm{P}_{1-x} / \mathrm{Si}$ dualjunction solar cell as a function of the top cell bandgap and threading dislocation density. The dashed line represents the optimal bandgap for each TDD. b) Optimal bandgap of the top cell and maximal theoretical efficiency of a flat surface (full line) and textured surface (dashed line) $\mathrm{GaAs}_{x} \mathrm{P}_{1-x} / \mathrm{Si}$ dual-junction solar cell as a function of the TDD

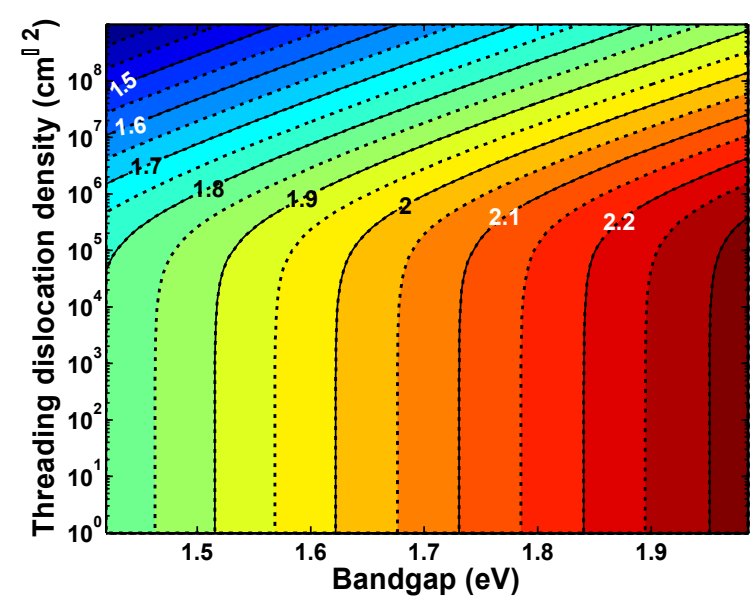

Figure 7. Open-circuit voltage $V_{o c}$ of a flat surface $\mathrm{GaAs}_{x} \mathrm{P}_{1-x} / \mathrm{Si}$ dual-junction solar cell as a function of the top cell bandgap and threading dislocation density. 


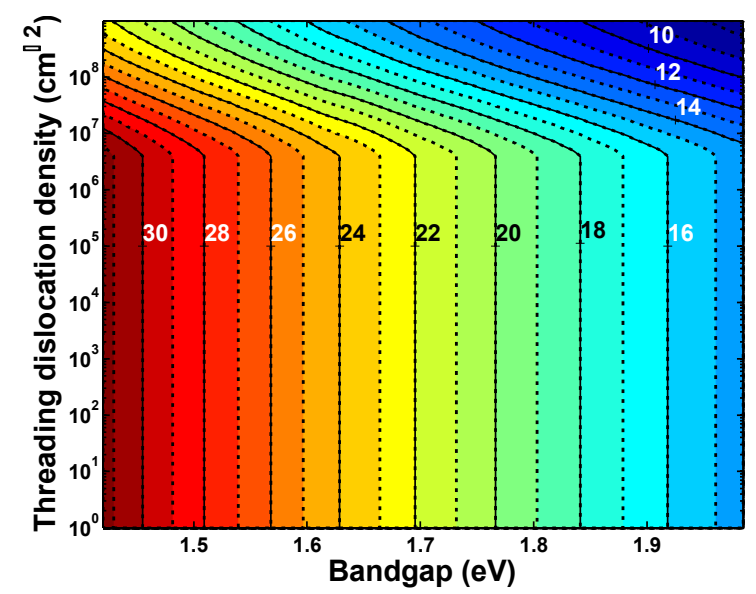

Figure 8. Short-circuit current density $J_{s c, t o p}$ of the top $\operatorname{GaAs}_{x} \mathrm{P}_{1-x}$ solar cell (flat surface) as a function of the top cell bandgap and threading dislocation density.

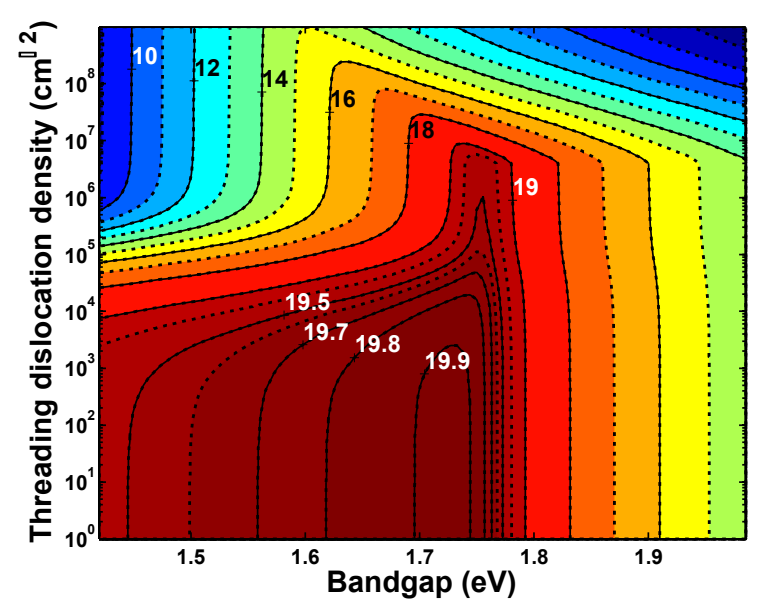

Figure 9. Maximum power point current density $J_{m p p}$ of a flat surface $\mathrm{GaAs}_{x} \mathrm{P}_{1-x} / \mathrm{Si}$ dual-junction solar cell as a function of the top cell bandgap and threading dislocation density.

FIGURE 9 shows the current density in the dual junction cell $(2-\mu \mathrm{m}$-thick top cell and flat surface) at the maximum power point (MPP). One important aspect is the impact of the threading dislocation density on the efficiency of the luminescent coupling. On the right part of the graph the MPP current density drops fast with increasing the top cell bandgap due to the absence of luminescent coupling, the current in the top cell being the limiting one due to a high top cell bandgap. On the bottom left part, the MPP current density is kept high thanks to the luminescent coupling. However, on the top left part of the graph where the TDD is high, the MPP current density drops fast in a similar way as in the absence of luminescent coupling. This phenomenon is due to the switching of the main source of recombinations in the top cell: at low TDDs, radiative recombinations dominate and an efficient luminescent coupling is possible. However, at higher TDDs, the non-radiative SRH recombinations due to the TDs take over the radiative ones and the luminescent coupling decreases to the point it gets null. Good current-matching between the cells is therefore needed for higher TDDs.

Note that our model here only approximates the impact of the reduced diffusion length on the short-circuit current. In particular for high defect densities, with carrier 
diffusion lengths shorter than the device thickness, the generation profile becomes very relevant for the carrier collection under short-circuit conditions. Since we work here with the approximation of a uniform generation rate, the results for $N_{T D}>10^{6} \mathrm{~cm}^{-}$ 2 are not a quantitatively accurate description of the impact of the dislocations. However, the qualitative trends are nevertheless reproduced by this simplifying approximation and therefore allow valuable qualitative insights for the design of future $\mathrm{GaAs}_{x} \mathrm{P}_{1-x} / \mathrm{Si}$ dual-junction solar cells. In particular, the quality of approximation increases with decreasing defect density. Therefore it approximates well for the range of material quality that is targeted in practice. A most notable result is that the efficiency drops very fast for $N_{T D}>10^{5} \mathrm{~cm}^{-2}$. We therefore conclude that a TDD of less than $10^{5} \mathrm{~cm}^{-2}$ should be targeted for practical devices. Further reduction in $N_{T D}$, though having a positive impact, does not yield such an increase in efficiency, especially once $N_{T D}<10^{4} \mathrm{~cm}^{-2}$.

\subsection{Evaluation of the real-world potential of the investigated $\operatorname{GaAs}_{x} \mathrm{P}_{1-x} / \mathrm{Si}$ dual- junction architecture}

Two factors strongly contributing to the losses of high efficiency industrial solar cells are relatively easy to integrate into our model: non-ideal EQE and surface recombinations at the top and bottom interfaces of both cells. A non-ideal EQE will mainly reduce the short-circuit current of the cells while the presence of surface recombinations will predominantly reduce their open-circuit voltage.

Dominant processes responsible for a non-ideal EQE are optical losses - such as shading from the front grid and reflection at the top surface - and high recombination rates of carriers generated close to the top and bottom surfaces, in particular carriers generated from high energy photons (blue light) in the emitter where the doping is strong and thereby the recombination rate is high. In order to simulate this impact, a multiplication coefficient $\xi$ can be added to the front absorptivities equations $(8,9,11,12)$ of individual GaAs and $\mathrm{Si}$ cells so that the experimental and theoretical short-circuit currents fit. Though $\xi$ only represents an average EQE and the wavelength dependence of the actual EQE is lost using this artifice, it allows to roughly simulate the impact of a non-ideal EQE on the short-circuit current. Using data for published results of very high efficiency Si and GaAs solar cells from Refs. $[44,45]$, average EQE of $\xi_{S i}=0.945$ and $\xi_{G a A s}=0.9$ are calculated. In our dual-junction architecture, as most of the high-energy photons are absorbed in the $\mathrm{GaAs}_{x} \mathrm{P}_{1-x}$ top cell, the absorption in the emitter of the silicon bottom cell, where the recombination rate is very high, will be small and a higher EQE in the silicon bottom cell is not incoherent.

Surface recombinations can be simulated by directly adding a surface recombination rate $R_{r \text {,surface }}(V)$ with an ideality factor of 1 to the flow-equilibrium equations $(22,23,25)$ :

$$
R_{r, \text { surface }, \text { Si } / G a A s}(V)=R_{r, \text { surface }, \text { Si } / G a A s, s c}\left(1-e^{\frac{q V}{k_{B} T}}\right)
$$

Note that, once multiplied by the elementary charge $q$, the voltage-independent part of the surface recombination rate $R_{r, \text { surface,Si/GaAs,sc }}$ represents the surface saturation current density so that $\mathrm{q} R_{r, \text { surface,Si/GaAs,sc }}=J_{0 e, S i / G a A s}$. Thereby:

$$
R_{r, \text { surface }, \text { Si } / G a A s}(V)=\frac{J_{0 e, S i / G a A s}}{q}\left(1-e^{\frac{q V}{k_{B} T}}\right)
$$


Experimental data have been published in Ref. [45] for the $1 k_{B} T$ component of the saturation current density for very high efficiency GaAs solar cells. The total saturation current density from Ref. [45] is the sum of the radiative recombination current density and the surface saturation current density. Using our model adapted to an individual GaAs solar cell, we can calculate the radiative recombination current density expected from such a device. This way a surface saturation current density $J_{0 e, G a A s}=2.75 \times 10^{-6}$ fA.cm ${ }^{-2}$ has been estimated. As the intrinsic carrier concentration of $\operatorname{GaAs}_{x} \mathrm{P}_{1-x}$ is smaller than the one of GaAs, the surface recombination parameter and consequently the surface saturation current density need to be normalized by the ratio $n^{2}{ }_{i, G a A s P} / n^{2}{ }_{i, G a A s}$, the surface recombination rate being linearly dependent on $n_{i}{ }^{2}$, in order to be applied to our dual-junction model. We therefore have:

$$
J_{0 e, t o p}=J_{0 e, G a A s} \times \frac{n_{i, G a A s P}^{2}}{n_{i, G a A s}^{2}}=2.75 \times 10^{-6} \times \frac{n_{i, G a A s P}^{2}}{n_{i, G a A s}^{2}} f A \cdot \mathrm{cm}^{-2}
$$

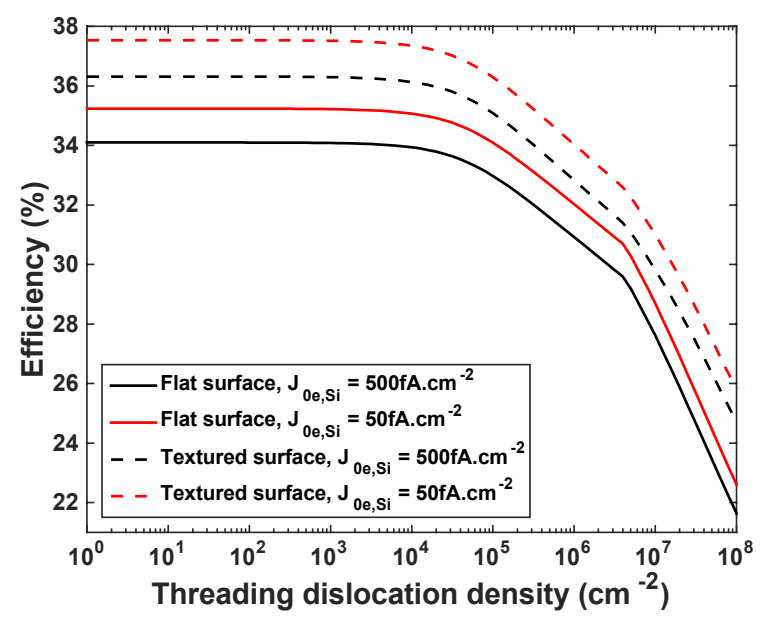

Figure 10. Maximal theoretical efficiency as a function of the TDD of flat surface (full lines) and textured surface (dashed lines) $\mathrm{GaAs}_{x} \mathrm{P}_{1-x} / \mathrm{Si}$ dual-junction solar cells with non-ideal EQE and different surface saturation current densities for the $\mathrm{Si}$ bottom cell

For the $\mathrm{GaAs}_{x} \mathrm{P}_{1-x}$ top cell, surface recombinations can easily be limited through standard processes - such as a window layer on the front side and a back surface field on the back side - so the best-in-class surface saturation current densities calculated for individual GaAs solar cells are probably achievable with the investigated architecture. However, for the silicon bottom cell, only advanced surface passivation techniques are able to yield very high efficiencies through low surface saturation current densities (around $25 \mathrm{fA} . \mathrm{cm}^{-2}$ for the top and bottom surfaces [46] so around 50 fA.cm ${ }^{-2}$ in total). These advanced passivation techniques are probably not compatible with epitaxial growth of III-V materials on silicon. As the passivation potential of the III-V/Si interface is unknown, the value of $50 \mathrm{fA} . \mathrm{cm}^{-2}$ appears very hopeful and only represents an upper limit on the cell performances. In the expected case where the III-V/Si interface does not efficiently passivate the silicon cell front surface, it is preferable to use very strong emitter doping densities with a sheet resistance range of e.g. 30 to $50 \Omega . \square^{-1}$. This will lead to a surface saturation current density for the bottom cell about one order of magnitude higher: in the range of 300 to $500 \mathrm{fA} . \mathrm{cm}^{-2}$ [46]. As we seek to provide an upper and a lower bound to the expectable realistic 
performances of a III-V/Si tandem junction, we have investigated the impact of two values for the silicon bottom cell surface saturation current density: $50 \mathrm{fA} . \mathrm{cm}^{-2}$ (unlikely best case scenario with very good passivation from the III-V/Si interface) and $500 \mathrm{fA} . \mathrm{cm}^{-2}$ (highly doped silicon bottom cell emitter).

FIGURE 10 shows the results of our model when taking into account these non-ideal EQEs and surface saturation currents for a $\mathrm{GaAs}_{x} \mathrm{P}_{1-x} / \mathrm{Si}$ dual-junction solar cell with a top cell thickness of $2 \mu \mathrm{m}$ and flat and ideally textured surfaces. Noteworthy results are also detailed in TABLE 2. For a flat surface, maximum efficiencies of $35.2 \%$ and $34.1 \%$ are respectively found for silicon bottom cell surface saturation current densities of 50 fA.cm ${ }^{-2}$ and 500 fA.cm ${ }^{-2}$ (37.5\% and $36.3 \%$ with a textured surface). The impact of relatively high surface recombination rates due to a strongly doped emitter is thus moderate (up to $1.2 \%$ absolute efficiency loss). Though the optimization of the silicon front-side passivation should be considered at some point, it is not a priority as yet. Comparatively, texturing the front side presents greater efficiency improvements (up to $2.2 \%$ ) and is of higher interest in the short term. These maximal efficiencies are barely impacted by the TDD up to $N_{T D}=10^{4} \mathrm{~cm}^{-2}$. For $N_{T D}>10^{4} \mathrm{~cm}^{-2}$ the maximal efficiencies drop pretty fast and, at $N_{T D}=10^{7} \mathrm{~cm}^{-2}$, reach a level comparable with or lower than the best single junction solar cells achieved so far [47].

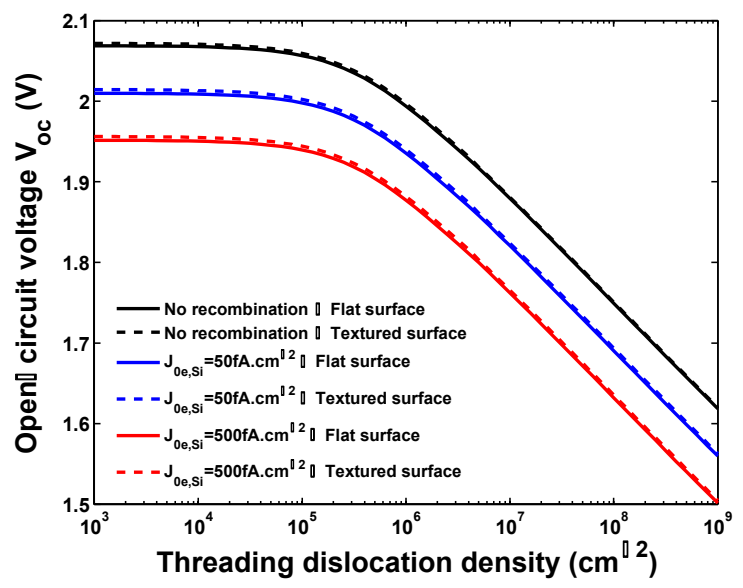

Figure 11. Open-circuit voltage $V_{o c}$ as a function of the TDD of flat surface (full lines) and textured surface (dashed lines) $\mathrm{GaAs}_{x} \mathrm{P}_{1-x} / \mathrm{Si}$ dual-junction solar cells with a $1.7 \mathrm{eV} \mathrm{GaAs} x \mathrm{P}_{1-x}$ top cell and different surface saturation current densities for the $\mathrm{GaAs}_{x} \mathrm{P}_{1-x}$ top cell and the Si bottom cell.

FIGURE 11 gives more insights on the impact of the surface recombinations on the open-circuit voltage of the tandem junction solar cell. The drop of $V_{o c}$ due to taking into consideration non-perfect $\mathrm{EQE}$ and surface recombinations in both cells is about $60 \mathrm{mV}$ and $120 \mathrm{mV}$ for silicon bottom cell surface saturation current densities of respectively $50 \mathrm{fA} . \mathrm{cm}^{-2}$ and $500 \mathrm{fA} . \mathrm{cm}^{-2}$. It is to be noted that the light trapping has barely any impact on the open-circuit voltage, the boost in efficiency with light trapping being due to an increase in $J_{s c}$.

These results show again that a TDD smaller than $10^{5} \mathrm{~cm}^{-2}$ in the $\operatorname{GaAs}_{x} \mathrm{P}_{1-x}$ active region should be targeted to harness the full potential of $\mathrm{GaAs}_{x} \mathrm{P}_{1-x} / \mathrm{Si}$ tandem solar cells. However, up to $N_{T D}=10^{6} \mathrm{~cm}^{-2}$, efficiencies over $30 \%$ are still achievable. It 
should be noted that these are rough estimations as the model does not take into account series resistance inside the cells that would reduce the fill factor of the cell and henceforth its efficiency by up to a couple of absolute percent. Moreover, the average EQEs used here do not fully describe the collection efficiency on both ends of the absorption spectrum, specifically for the Si bottom cell in this case.

\subsection{Comparison with experimental data}

As III-V on Si multijunction solar cells is still an early stage technology, directly comparing experimental and theoretical efficiencies of $\mathrm{GaAs}_{x} \mathrm{P}_{1-x} / \mathrm{Si}$ dual-junction cells offers a limited interest as early stage devices suffer from a lot of non-idealities, such as high series resistance responsible for low fill factors, absence of an antireflection coating leading to low short-circuit currents, poor current-matching between the cells or non-optimized silicon bottom cell. Moreover, GaAs $\mathrm{P}_{x} \mathrm{P}_{1-x}$ cells with varying bandgaps have been fabricated, making the comparison even harder. However, an important parameter that can easily be compared between non-optimized cells of different bandgaps is the bandgap-voltage offset of the top cell, defined as $W_{o c}=q E_{g}-V_{o c}$. Additionally, as the open-circuit voltage of the top cell is the main limiting parameter for the performances of the dual-junction, studying the $W_{o c}$ allows for meaningful comparison between theoretical and experimental results.

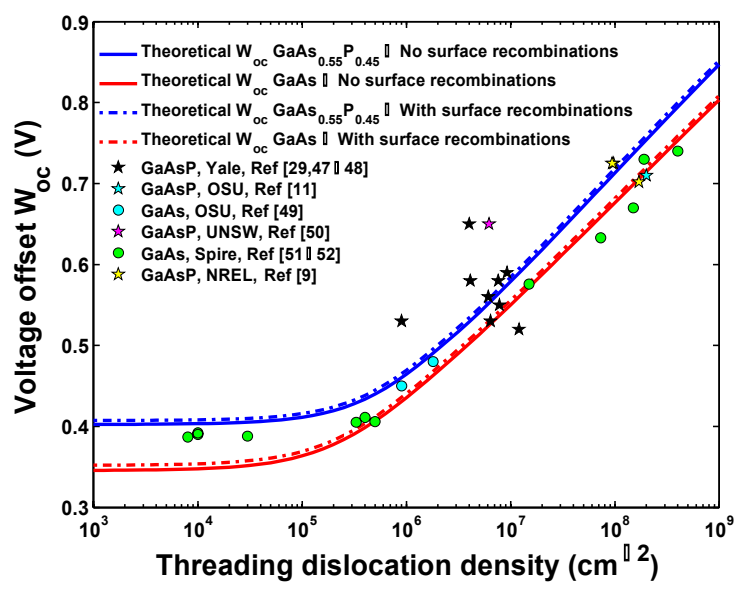

Figure 12. Comparison of theoretical and experimental [9,11,30,48-53] bandgapvoltage offset $W_{o c}=q E_{g}-V_{o c}$ as a function of the TDD for GaAs and $\mathrm{GaAs}_{x} \mathrm{P}_{1-x}$ solar cell. The cell is supposed to have a flat surface with no light trapping.

FIGURE 12 shows our calculated $W_{o c}$ for GaAs and $\mathrm{GaAs}_{0.55} \mathrm{P}_{0.45}$, representing the boundaries of direct bandgap $\operatorname{GaAs}_{x} \mathrm{P}_{1-x}$, as a function of the TDD with and without surface recombinations, as introduced in section 3.4. Experimental data points from different research groups $[9,11,30,48-53]$ have been added, with $\mathrm{GaAs}_{x} \mathrm{P}_{1-x}$ and GaAs cells grown on different substrates such as $\mathrm{GaP}, \mathrm{GaP} / \mathrm{Si}$, GaAs, GaAsP/GaAs and $\mathrm{SiGe} / \mathrm{Si}$. It is to be noted that, because of the low level of surface recombination assumed, surface recombinations have a very limited impact on the $W_{o c}$. The experimental data is in strong agreement with the theoretical model. For GaAs cells, the full range of TDD has been investigated and reducing the $W_{o c}$ for low TDDs becomes harder as other sources of recombinations begin to dominate, hence the lowest $W_{o c}$ values concentrated around $0.4 \mathrm{~V}$ even for TDDs around $10^{4} \mathrm{~cm}^{-2}$. For $\mathrm{GaAs}_{x} \mathrm{P}_{1-x}$, few data points are available for a TDD below $4 \times 10^{6} \mathrm{~cm}^{-2}$. Breaking the 
$0.5 \mathrm{~V} W_{o c}$-limit will need further work in order to reduce the TDD by at least an order of magnitude.

\section{CONCLUSION}

A theoretical model has been developed for $\mathrm{GaAs}_{x} \mathrm{P}_{1-x} / \mathrm{Si}$ dual-junction solar cell. Using the blackbody theory extended to semiconductors and flow equilibrium in the cells, the number of parameters needed for the modeling has been reduced to a minimum. Impact of Auger recombinations in the Si bottom cell and threading dislocations-induced Shockley-Read-Hall recombinations in the top $\operatorname{GaAs}_{x} \mathrm{P}_{1-x}$ cell have been taken into account. Flat and ideally textured surface geometries have also been investigated as well as the luminescent coupling between the cells.

For non-optimal bandgaps, the luminescent coupling greatly increases the efficiency of the dual-junction cell by rebalancing the currents between the two cells. This strongly improves the flexibility in the design and the operations of such cells. However, at high TDDs, the luminescent coupling is strongly reduced as nonradiative recombinations take over radiative recombinations.

For tandem cells with $\mathrm{GaAs}_{x} \mathrm{P}_{1-x}$ top and Si bottom junctions, top cell thickness and surface texturing have a strong impact for less than $1-\mu \mathrm{m}$-thick top cells. Above $1 \mu \mathrm{m}$ the impact is reduced, with a calculated theoretical maximal efficiency of $39.6 \%$ and $41.8 \%$ for a $5-\mu \mathrm{m}$-thick top cell with a flat and an ideally textured surface, respectively.

For a $2-\mu \mathrm{m}$-thick top cell, the threading dislocation density (TDD) has a very limited impact on the cell efficiency for values up to $N_{T D}=10^{4} \mathrm{~cm}^{-2}$. For TDD values between $10^{4} \mathrm{~cm}^{-2}$ and $4 \times 10^{6} \mathrm{~cm}^{-2}$, the efficiency is reduced because of the reduction in opencircuit voltage and fill factor due to the increased threading-dislocation-related Shockley-Read-Hall recombination rate. For a density of threading dislocations above $4 \times 10^{6} \mathrm{~cm}^{-2}$, the photon collection and short-circuit current are also impacted as the diffusion length of the minority carriers in the base is getting smaller than the thickness of the base. The optimal bandgap of the top $\operatorname{GaAs}_{x} \mathrm{P}_{1-x}$ cell is therefore also impacted.

By using non-ideal EQEs and short-circuit surface recombination rates extracted from best-in-class Si and GaAs cells data, it is possible to give a rough estimation of the potential of the investigated architecture. For a threading dislocation density of $10^{5} \mathrm{~cm}^{-2}$, an efficiency of up to $33.0 \%$ could be achieved for a $\mathrm{GaAs}_{x} \mathrm{P}_{1-x} / \mathrm{Si}$ tandem cell with a flat surface, a 2- $\mu \mathrm{m}$-thick $\mathrm{GaAs}_{x} \mathrm{P}_{1-x}$ top cell and realistic levels of surface recombinations at the III-V/Si interface. The efficiency increases to $35.1 \%$ with a textured surface.

Comparing the results of our model with published experimental data, a strong agreement is found regarding the bandgap-voltage offset $W_{o c}$ of the top cell as a function of the TDD. This proves the robustness of our model. The framework of this model could be used for other dual-junction architectures with different top and bottom cell materials. Additionally, as more experimental work is carried out on $\mathrm{GaAs}_{x} \mathrm{P}_{1-x} / \mathrm{Si}$ dual-junction architectures, this model can be used to better understand experimental results and design future cells. 


\section{ACKNOWLEDGEMENTS}

The authors thank Dr. Jiang Wu for his help in the elaboration of this publication. This work is supported by Total SA. H. Liu would like to thank The Royal Society for funding his University Research Fellowship.

\section{REFERENCES}

1. Masuko K, Shigematsu M, Hashiguchi T, Fujishima D, Kai M, Yoshimura N, Yamaguchi T, Ichihashi Y, Mishima T, Matsubara N, Yamanishi T, Takahama T, Taguchi M, Maruyama E, Okamoto S. Achievement of More Than 25\% Conversion Efficiency With Crystalline Silicon Heterojunction Solar Cell. IEEE J. Photovolt. 4 (6) (2014) 1433-1435, DOI: 10.1109/JPHOTOV.2014.2352151

2. Smith DD, Cousins P, Westerberg S, De Jesus-Tabajonga R, Aniero G, Shen YC. Toward the Practical Limits of Silicon Solar Cells. IEEE J. Photovolt. 4 (6) (2014) 1465-1469, DOI: 10.1109/JPHOTOV.2014.2350695

3. Takamoto $\mathrm{T}$, Washio $\mathrm{H}$, Juso H. Application of $\mathrm{InGaP} / \mathrm{GaAs} / \mathrm{InGaAs}$ Triple Junction Solar cells to Space Use and Concentrator Photovoltaic. Proc. $40^{\text {th }}$ IEEE PVSC (2014) 1-5, DOI: 10.1109/PVSC.2014.6924936

4. Chiu PT, Law DC, Woo RL, Singer SB, Bhusari D, Hong WD, Zakaria A, Boisvert J, Mesropian S, King RR, Karam NH. 35.8\% space and 38.8\% terrestrial 5J direct bonded cells. Proc. 40 ${ }^{\text {th }}$ IEEE PVSC (2014) 11-13, DOI: 10.1109/PVSC.2014.6924957

5. Kayes BM, Zhang L, Twist R, Ding IK, Higashi GS. Flexible Thin-Film Tandem Solar Cells With $>30 \%$ Efficiency. IEEE J. Photovolt. 4 (2) (2014) 729-733, DOI: 10.1109/JPHOTOV.2014.2299395

6. Dimroth F, Roesener T, Essig S, Weuffen C, Wekkeli A, Oliva E, Siefer G, Volz K, Hannappel T, Häussler D, Jäger W, Bett AW. Comparison of Direct Growth and Wafer Bonding for the Fabrication of GaInP/GaAs Dual-Junction Solar Cells on Silicon. IEEE J. of Photovolt. 4 (2) (2014) 620-625, DOI: 10.1109/JPHOTOV.2014.2299406

7. Hayashi K, Soga T, Nishikawa H, Jimbo T, Umeno M. MOCVD growth of GaAsP on Si for tandem solar cell applications. Proc. $1^{\text {st }}$ IEEE WCPEC (1994) 1890-1893, DOI: 10.1109/WCPEC.1994.520736

8. Geisz JF, Olson JM, Friedman DJ, Jones KM, Reedy RC, Romero MJ. Lattice-matched GaNAsP-on-Silicon Tandem Solar. Proc. $3^{\text {rd }}$ IEEE WCPEC (2005) 695-698, DOI: 10.1109/PVSC.2005.1488226.

9. Geisz JF, Olson JM, Romero MJ, Jiang CS, Norman AG. Lattice-mismatched GaAsP Solar Cells Grown on Silicon my OMVPE. Proc. $4^{\text {th }}$ IEEE WCPEC (2006) 772-775, DOI: 10.1109/WCPEC.2006.279570

10. Grassman TJ, Brenner MR, Carlin AM, Rajagopalan S, Unocic R, Dehoff R, Mills M, Fraser H, Ringel SA. Toward Metamorphic Multijunction GaAsP/Si Photovoltaics Grown on Optimized GaP/Si Virtual Substrates Using AnionGraded GaAsy $\mathrm{P}_{1-\mathrm{y}}$ Buffers. Proc. 34 $4^{\text {th }}$ IEEE PVSC (2009) 2016-2021, DOI: 10.1109/PVSC.2009.5411489

11. Grassman TJ, Brenner MR, Gonzalez M, Carlin AM, Unocic R, Dehoff R, Mills M, Ringel SA. Characterization of Metamorphic GaAsP/Si Materials and Devices for Photovoltaic Applications. IEEE Trans. Electron Devices 57 (12) (2010) 3361-3369, DOI: 10.1109/TED.2010.2082310 
12. Lang JR, Faucher F, Tomasulo S, Nay Yaung K, Lee ML. Comparison of GaAsP solar cells on GaP and GaP/Si. Appl. Phys. Lett. 103 (2013) 092102, DOI: $10.1063 / 1.4819456$

13. Nell ME, Barnett AM. The Spectral p-n Junction Model for Tandem Solar-Cell Design. IEEE Trans. Electron Devices 34 (2) (1987) 257-266, DOI: 10.1109/TED.1987.22916

14. Wanlass MW, Emery KA, Gessert TA, Horner GS, Osterwald CR, Coutts TJ. Practical Considerations in Tandem Cell Modeling. Sol. Cells 27 (1-4) (1989) 191-204, DOI: 10.1016/0379-6787(89)90028-8

15. Kurtz SR, Faine P, Olson JM. Modeling of two-junction, series-connected tandem solar cells using top-cell thickness as an adjustable parameter. J. Appl. Phys. 68 (4) (1990) 1890-1895, DOI: 10.1063/1.347177

16. Shockley W, Queisser HJ. Detailed Balance Limit of Efficiency of p-n Junction Solar Cells. J. Appl. Phys. 32 (3) (1961) 510-519, DOI: 10.1063/1.1736034

17. Standard Tables for Reference Solar Spectral Irradiances: Direct Normal and Hemispherical on 37 degree Tilted Surface, ASTM G173-03, 2012; http://rredc.nrel.gov/solar/spectra/am1.5/ accessed on September $23^{\text {rd }} 2014$

18. Vurgaftman I, Meyer JR, Ram-Mohan LR. Band parameters for III-V compound semiconductors and their alloys. J. Appl. Phys. 89 (11) (2001) 5815-5875, DOI: $10.1063 / 1.1368156$

19. Basic parameters, Band structure and carrier concentration and Electrical Parameters of $G a_{x} I n_{1-x} A s_{y} P_{1-y}$, Ioffe Physical Technical Institute; http://www.ioffe.ru/SVA/NSM/Semicond/GaInAsP/index.html accessed on September $23^{\text {rd }} 2014$

20. Basic parameters, Band structure and carrier concentration and Electrical Parameters of GaAs, Ioffe Physical Technical Institute; http://www.ioffe.ru/SVA/NSM/Semicond/GaAs/index.html accessed on September $23^{\text {rd }} 2014$

21. Ito H, Ishibashi T. Minority electron Mobility in p-type GaAs. J. Appl. Phys. 65 (12) (1989) 5197-5199, DOI: 10.1063/1.343150

22. Aspnes DE, Kelso SM, Logan RA, Bhat R. Optical properties of $\mathrm{Al}_{\mathrm{x}} \mathrm{Ga}_{1-\mathrm{x}} \mathrm{As} . J$. Appl. Phys. 60 (2) (1986) 754-767, DOI: 10.1063/1.337426

23. Miller OD, Yablonovitch E, Kurtz SR. Strong Internal and External Luminescence as Solar Cells Approach Shockley-Queisser Limit. IEEE J. Photovolt. 2 (3) (2012) 303-311, DOI: 10.1109/JPHOTOV.2012.2198434

24. Sturge MD. Optical Absorption of Gallium Arsenide between 0.6 and $2.75 \mathrm{eV}$. Physical Rev. 127 (3) (1962) 768-773, DOI: 10.1103/PhysRev.127.768

25. Green MA, Keevers MJ. Optical Properties of Intrinsic Silicon at 300 K. Prog in Photovol. Res. Appl. 3 (1995) 189-192, DOI: 10.1002/pip.4670030303

26. Faucher J, Gerger A, Tomasulo S, Ebert C, Lochtefeld A, Barnett A, Lee ML. Single-junction GaAsP solar cells grown on SiGe graded buffers on Si. Appl. Phys. Lett. 103 (2013) 191901, DOI: 10.1063/1.4828879

27. Sinton RA, Swanson RM. Recombination in Highly Injected Silicon. IEEE Trans. Electron Devices 34 (6) (1987) 1380-1389, DOI: 10.1109/T-ED.1987.23095

28. Würfel P. The Chemical Potential of Radiation. J. Phys. C Solid State Phys. 15 (18) (1982) 3967-3985, DOI: 10.1088/0022-3719/15/18/012

29. Yablonovitch E, Cody GD. Intensity Enhancement in Textured Optical Sheets for Solar Cells. IEEE Trans. Electron Devices 29 (2) (1982) 300-305, DOI: 10.1109/T-ED.1982.20700 
30. Yamaguchi M, Amano C. Efficiency calculations of thin-film GaAs solar cells on Si substrates. J. Appl. Phys. 58 (9) (1985) 3601-3606, DOI: 10.1063/1.335737

31. Yamaguchi M. Dislocation density reduction in heteroepitaxial III-V compound films on Si substrates for optical devices. J. Mater. Res. 6 (2) (1991) 376-384, DOI: 10.1557/JMR.1991.0376

32. Yang MJ, Yamaguchi M, Takamoto $T$, Ikeda E, Kurita H, Ohmori M. Photoluminescence analysis of InGaP top cells for high-efficiency multi-junction solar cells. Sol. Energy Mater. Sol. Cells 45 (4) (1997) 331-339, DOI: 10.1016/S0927-0248(96)00079-7

33. Sieg RM, Carlin JA, Boeckl JJ, Ringel SA, Currie MT, Ting SL, Langdo TA, Taraschi G, Fitzgerald EA, Keyes BM. High minority-carrier lifetimes in GaAs grown on low-defect-density Ge/GeSi/Si substrates. Appl. Phys. Lett. 73 (21) (1998) 3111-3113, DOI: 10.1063/1.122689

34. Yamaguchi M, Ohmachi Y, Oh'hara T, Kadota Y, Imaizumi M, Matsuda S. GaAs Solar Cells Grown on Si Substrates for Space Use. Prog Photovolt. Res. Appl. 9 (3) (2001) 191-201, DOI: 10.1002/pip.366

35. Carlin JA, Ringel SA, Fitzgerald EA, Bulsara M. High-lifetime GaAs on Si using GeSi buffers and its potential for space photovoltaics. Sol. Energy Mater. Sol. Cells 66 (1-4) (2001) 621-630, DOI: 10.1016/S0927-0248(00)00250-6

36. Andre CL, Boeck1 JJ, Wilt DM, Pitera AJ, Lee ML, Fitzgerald EA, Keyes BM, Ringel SA. Impact of dislocations on minority carrier electron and hole lifetimes in GaAs grown on metamorphic SiGe substrates. Appl. Phys. Lett. 84 (18) (2004) 3447-3449, DOI: 10.1063/1.1736318

37. Andre CL, Wilt DM, Pitera AJ, Lee ML, Fitzgerald EA, Ringel SA. Impact of dislocation densities on $\mathrm{n}+/ \mathrm{p}$ and $\mathrm{p}+/ \mathrm{n}$ junction GaAs diodes and solar cells on SiGe virtual substrates. Appl. Phys. Lett. 98 (2005) 014502, DOI: 10.1063/1.1946194

38. Grover S, Li JV, Young DL, Stradins P, Branz HM. Reformulation of solar cell physics to facilitate experimental separation of recombination pathways. Appl. Phys. Lett. 103 (2013) 093502, DOI: 10.1063/1.4819728

39. Ringel SA, Carlin JA, Andre CL, Hudait MK, Gonzalez M, Wilt DM, Clark EB, Jenkins P, Scheiman D, Allerman A, Fitzgerald EA, Leitz CW. Single-junction InGaP/GaAs Solar Cells Grown on Si Substrates with SiGe Buffer Layers. Prog Photovolt. Res. Appl. 10 (6) (2002) 417-426, DOI: 10.1002/pip.448

40. Friedman DJ, Geisz JF, Steiner MA. Effect of Luminescent Coupling on the Optimal Design of Multijunction Solar Cells. IEEE J. Photovolt. 4 (3) (2014) 986-990, DOI: 10.1109/JPHOTOV.2014.2308722

41. Friedman DJ, Geisz JF, Steiner MA. Analysis of Multijunction Solar Cell Current-Voltage Characteristics in the Presence of Luminescent Coupling. IEEE J. Photovolt. 3 (4) (2013) 1429-1436, DOI: 10.1109/JPHOTOV.2013.2275189

42. Steiner MA, Geisz JF. Non-linear luminescent coupling in series-connected multijunction solar cells. Appl. Phys. Lett. 100 (2012) 251106, DOI: $10.1063 / 1.4729827$

43. Brown AS, Green MA. Radiative coupling as a means to reduce spectral mismatch in monolithic tandem solar cells tacks - Theoretical considerations. Proc. $29^{\text {th }}$ IEEE PVSC (2002) 868-871, DOI: 10.1109/PVSC.2002.1190717

44. Zhao J, Wang A, Green MA. High efficiency PERL and PERT silicon solar cells on FZ and MCZ substrates. Sol. Energy Mater. Sol. Cells 65 (2001) 429-435, DOI: $10.1016 / \mathrm{S} 0927-0248(00) 00123-9$ 
45. Kayes BM, Nie H, Twist R, Spruytte SG, Reinhardt F, Kizilyalli IC, Higashi GS. $27.6 \%$ conversion efficiency, a new record for single-junction solar cells under 1-sun illumination. Proc. 37 $7^{\text {th }}$ IEEE PVSC (2011) 000004-000008, DOI: 10.1109/PVSC.2011.6185831

46. Kerr MJ, Schmidt J, Cuevas A, Bultman JH. Surface recombination velocity of phosphorus-diffused silicon solar cell emitters passivated with plasma enhanced chemical vapor deposited silicon nitride and thermal silicon oxide. J. Appl. Phys. 89 (7) (2001) 3821-3826, DOI: 10.1063/1.1350633

47. Green MA, Emery KA, Hishikawa Y, Warta W, Dunlop ED. Solar cell efficiency tables (version 45). Prog Photovolt. Res. Appl. 23 (2015) 1-9, DOI: 10.1002/pip.2573

48. Nay Yaung K, Lang JR, Lee ML. Towards high efficiency GaAsP solar cells on (001) GaP/Si. Proc. 40 IEEE PVSC (2014) 0831-0835, DOI: 10.1109/PVSC.2014.6925043

49. Tomasulo S, Nay Yaung K, Simon J, Lee ML. GaAsP solar cells on GaP substrates by molecular beam epitaxy. Appl. Phys. Lett. 101 (2012) 033911, DOI: $10.1063 / 1.4738373$

50. Andre CL, Carlin JA, Boeckl JJ, Wilt DM, Smith MA, Pitera AJ, Lee ML, Fitzgerald EA, Ringel SA. Investigations of High-Performance GaAs Solar Cells Grown on $\mathrm{Ge}-\mathrm{Si}_{1-\mathrm{x}} \mathrm{Ge}_{\mathrm{x}}-\mathrm{Si}$ Substrates. IEEE Trans. Electron Devices 52 (6) (2005) 1055-1060, DOI: 10.1109/TED.2005.848117

51. Schmieder KJ, Gerger A, Pulwin Z, Wang L, Diaz M, Curtin M, Ebert C, Lochtefeld A, Opila RL, Barnett A. GaInP Window Layers for GaAsP on SiGe/Si Single and Dual-Junction Solar Cells. Proc. 39 ${ }^{\text {th }}$ IEEE PVSC (2013) 2462-2465, DOI: 10.1109/PVSC.2013.6744974

52. Vernon SM, Tobin SP, Haven VE, Bajgar C, Dixon TM, Al-Jassim MM, Ahrenkiel RK, Emery KA. Efficiency improvements in GaAs-on-Si solar cells. Proc. 20 ${ }^{\text {th }}$ IEEE PVSC (1988) 481-485, DOI: 10.1109/PVSC.1988.105704

53. Vernon SM, Tobin SP, Al-Jassim MM, Ahrenkiel RK, Jones KM, Keyes BM. Experimental study of solar cell performance versus dislocation density. Proc. $21^{\text {th }}$ IEEE PVSC (1990) 211-216, DOI: 10.1109/PVSC.1990.111619 


\begin{tabular}{|c|c|c|}
\hline Electronic Parameter & Formula & Source \\
\hline Bandgap & $\begin{array}{l}E_{g}\left(\operatorname{GaAs}_{x} P_{1-x}\right)= \\
1.42 x+2.78(1-x)-0.19 x(1-x)\end{array}$ & {$[18]$} \\
\hline $\begin{array}{l}\text { Density of states in } \\
\text { the conduction band }\end{array}$ & $\begin{array}{l}N_{c}\left(G a A s_{x} P_{1-x}\right)= \\
5.6 \times 10^{19}(0.08-0.039 x)^{\frac{3}{2}}\end{array}$ & $\begin{array}{l}\text { Extrapolated from [19] } \\
\text { and [20] }\end{array}$ \\
\hline $\begin{array}{l}\text { Density of states in } \\
\text { the valence band }\end{array}$ & $\begin{array}{l}N_{v}\left(G a A s_{x} P_{1-x}\right)= \\
2.9 \times 10^{19}(0.6-0.18 x)^{\frac{3}{2}}\end{array}$ & $\begin{array}{l}\text { Extrapolated from [19] } \\
\text { and [20] }\end{array}$ \\
\hline $\begin{array}{l}\text { Diffusion coefficient } \\
\text { of electrons }\end{array}$ & $\begin{array}{l}D_{n}\left(G a A s_{x} P_{1-x}\right)= \\
39-57 x+108 x^{2}\end{array}$ & $\begin{array}{l}\text { Extrapolated from [19] } \\
\text { and }[20] \text { with } \\
\text { corrections from [21] }\end{array}$ \\
\hline $\begin{array}{l}\text { Diffusion coefficient } \\
\text { of holes }\end{array}$ & $\begin{array}{l}D_{p}\left(\mathrm{GaAs} s_{x} P_{1-x}\right)= \\
5-10 x+12.5 x^{2}\end{array}$ & $\begin{array}{l}\text { Extrapolated from [19] } \\
\text { and [20] }\end{array}$ \\
\hline Relative permittivity & $\varepsilon_{r}\left(G a A s_{x} P_{1-x}\right)=12.9$ & $\begin{array}{l}\text { Extrapolated from [19] } \\
\text { and [20] }\end{array}$ \\
\hline
\end{tabular}

Table 1. Formulas used for the calculation of the electronic parameters of the materials investigated with the respective sources 


\begin{tabular}{|c|c|c|c|c|c|c|}
\hline \multirow{2}{*}{$\begin{array}{l}\text { Surface } \\
\text { geometry }\end{array}$} & \multirow{2}{*}{$\begin{array}{c}\mathbf{J}_{0 e, b o t t o m} \\
\left(\mathbf{f A} \cdot \mathbf{c m}^{-2}\right)\end{array}$} & \multicolumn{5}{|c|}{ Efficiency (\%) } \\
\hline & & $\begin{array}{c}N_{T D}= \\
10^{0} \mathbf{c m}^{-2}\end{array}$ & $\begin{array}{c}N_{T D}= \\
10^{4} \mathrm{~cm}^{-2}\end{array}$ & $\begin{array}{c}N_{T D}= \\
10^{5} \mathrm{~cm}^{-2}\end{array}$ & $\begin{array}{c}N_{T D}= \\
10^{6} \mathrm{~cm}^{-2}\end{array}$ & $\begin{array}{c}\mathrm{N}_{\mathrm{TD}}= \\
10^{7} \mathrm{~cm}^{-2}\end{array}$ \\
\hline \multirow{2}{*}{ Flat } & 50 & 35.2 & 35.1 & 34.1 & 32.0 & 28.7 \\
\hline & 500 & 34.1 & 33.9 & 33.0 & 30.9 & 27.6 \\
\hline \multirow{2}{*}{$\begin{array}{l}\text { Ideally } \\
\text { textured }\end{array}$} & 50 & 37.5 & 37.4 & 36.3 & 34.0 & 31.0 \\
\hline & 500 & 36.3 & 36.1 & 35.1 & 32.8 & 29.8 \\
\hline
\end{tabular}

Table 2. Efficiencies of dual-junction $\mathrm{GaAs}_{x} \mathrm{P}_{1-x} / \mathrm{Si}$ solar cells for different front surface geometries (flat and ideally textured) and silicon bottom cell surface saturation current densities $\mathbf{J}_{0 e, b o t t o m}$. 